\title{
Da Crítica Genética à Crítica de Processo: uma linha de pesquisa em expansão
}

Genetic Criticism to Process Criticism: A Research line in EXPANSION

\section{Cecilia Almeida Salles*}

Resumo: O artigo apresenta o histórico das pesquisas de crítica genética, assim como são desenvolvidas no Programa de Pós-Graduação em Comunicação e Semiótica da PUC/SP. São discutidas a ampliação dos objetos de pesquisa e as adequações terminológicas e metodológicas, a partir de publicações e do desenvolvimento de uma grande diversidade de mestrados e doutorados. Para além dessas duas questões, são apresentados alguns outros marcos do desenvolvimento de tais pesquisas como o percurso teórico dos estudos de caso a uma teoria geral da criação, de base semiótica e a formação de uma linha de pesquisa. Os caminhos tomados por esses estudados geraram a renovação dos objetivos da crítica genética, passando a ser a compreensão dos processos de criação, a partir de metodologias diversas. Trata-se de uma alteração bastante significativa, estreitamente relacionada a outra proposta do artigo de discutir o conceito de criação como rede, em diálogo com a experimentação contemporânea. Neste contexto é proposta uma crítica de processos de criação, para além de algumas delimitações da crítica genética. Palavras-chave: Processo de criação. Crítica de processo. Crítica genética.

Abstract: The article presents the historic of the genetic criticism researches, as they are developed in the Program of Comunication and Semiotics (PUC/ SP). The expansion of research subjects and methodological adjustments are

\footnotetext{
* Doutora em Linguística Aplicada e Estudos de Línguas pela Pontifícia Universidade Católica de São Paulo (1990), onde atualmente ministra aulas no Programa de Pós-Graduação em Comunicação e Semiótica. Também é coordenadora do Centro de Estudos de Crítica Genética da PUC/SP. Contato: cecilia.salles@gmail.com.
} 
discussed, having as a starting point publications and the development of a wide range of masters and PHDs. In addition to these two questions, the article discusses some other milestones in the development of such research as the theoretical course of the case studies to a general theory of the creation of semiotic base and development of a line of research. These paths taken by these researches generated the renewal of genetic criticism goals, becoming the understanding of the processes of creation, making use of different methodologies. This is a very significant change, closely related to another proposal of the article to discuss the concept of creation as a network, in dialogue with contemporary experimentation. In this context, a process criticism is proposed beyond some delimitations of genetic criticism.

Keywords: Process of creation. Process criticism. Genetic criticism.

\section{Introdução}

As reflexões, que serão aqui desenvolvidas, fazem uso da própria perspectiva crítica de acompanhamento de processos de criação, para falar do percurso de uma pesquisa ao longo do tempo. Para tal empreitada, não se pode deixar de levar em conta os diferentes momentos históricos e contextos acadêmicos aos quais cada percurso está relacionado. Essas questões, de certa forma, direcionam buscas dos pesquisadores, determinando critérios de escolhas do modo como as pesquisas passaram a ser feitas.

A crítica genética, em seu início, oferecia uma metodologia para se discutir os processos de criação a partir dos registros de escritores e seus pesquisadores acessavam diferentes teorias para tal discussão como linguística, psicanálise etc.

Falo de uma crítica genética em expansão, no âmbito do Programa de Comunicação e Semiótica da Pontifícia Universidade Católica de São Paulo, que começou a ser desenvolvida no início dos anos 1990. Por algumas características interligadas, gerou certos desdobramentos, cujos marcos apresentarei a seguir.

Havia a convivência com classes formadas por alunos de formações e interesses bastante diversos, tais como jornalismo, publicidade, artes visuais, arquitetura, artes cênicas, cinema, literatura, design, etc. A interdisciplinaridade 
do corpo discente levou à necessidade de escolhas de caminhos de pesquisa que dessem conta de tal diversidade. Por outro lado, havia o diálogo com as teorias semióticas, especialmente nesse primeiro momento, a de Charles S. Peirce, que propõe instrumentos teóricos de natureza bastante geral, que serão discutidos mais adiante.

\section{Ampliação dos Objetos de Estudo}

Como consequência dessas duas questões, surgiu a possibilidade de se falar em crítica genética para além da literatura. Acreditava-se que esta ampliação já estava inscrita na própria definição de seu propósito e de seu objeto de estudo.

Se o propósito direcionador dos estudos genéticos foi, desde seu início, a compreensão do processo de produção de uma obra literária e seu objeto de estudo eram os registros deste percurso do escritor, encontrados nos manuscritos, deveria necessariamente romper a barreira da literatura e ampliar seus limites para além da palavra. Processo e registros são independentes da materialidade na qual a obra se manifesta e independentes, também, das linguagens nas quais estas pegadas se apresentam. É possível, portanto, conhecer alguns procedimentos da criação, em qualquer manifestação artística, a partir dos rastros deixados pelos artistas.

Voltando ao contexto acadêmico, a ampliação dos objetos de estudo da literatura para as artes em geral não era suficiente, pois surgiam também pesquisadores interessados nos processos jornalísticos e publicitários. Daí o Centro de Estudos de Crítica Genética, fundado em 1993, já se dedicar ao processo de criação nas artes e nas mídias.

O livro Crítica genética: uma introdução, em sua primeira edição (1992), pressentia esses futuros desdobramentos. Referindo-me às pesquisas sobre o manuscrito literário, constatava, no capítulo "Horizontes da Crítica Genética" que "foi assim que nasceram e assim estão sendo desenvolvidas as pesquisas até o momento. No entanto, sabemos ser inevitável a necessidade de ampliar seus limites. Certamente, ouviremos falar, em muito pouco tempo, sobre estudos de manuscritos em artes plásticas, música, teatro, arquitetura e manuscritos científicos. Isto oferece novas perspectivas para pesquisas sobre as especificidades e as generalidades dos processos criativos artísticos e para 
não mencionar a possibilidade de se adentrar o interessante campo de pesquisa dedicado à relação ciência/arte - agora sob a ótica genética" (SALLES, 1992, p. 106).

Essa possibilidade foi concretizada em alguns anos. A Crítica Genética assume, desse modo, aquilo que Daniel Ferrer (2000, p. 49), no congresso da Associação de Pesquisadores do Manuscrito Literário, de 1999, chamou de "vocação transartística". Afirmou que o desenvolvimento dos estudos genéticos sustentava-se nos esforços de alguns pesquisadores de "promover uma reflexão da crítica genética que atravesse as fronteiras dos gêneros e das artes", mencionando o grupo de pesquisa da PUC/SP. Ele via que esse era o caminho para os estudos genéticos sobreviverem no século XXI.

Assim, essas pesquisas passaram a oferecer outra abordagem crítica para a literatura, artes e mídias, sob o ponto de vista de seus processos de produção, não em detrimento das críticas sobre os objetos assim como são mostrados publicamente (crítica literária, arte, cinema, etc.). O acesso aos arquivos da criação (anotações, diários, esboços, etc.) gera a compreensão sobre algumas das camadas que sustentam as escolhas dos artistas que, naturalmente, ressignificam a obra.

Discutindo, ainda, a ampliação de seus objetos e fazendo um salto no tempo, desenvolvi em minha pesquisa de pós-doutorado (2015/2016), um estudo sobre a complexidade dos processos em grupo, como teatro, cinema, dança, etc.

\section{Percurso do Específico ao Geral}

A abordagem semiótica, uma teoria geral dos signos, associada à natureza de minhas buscas como pesquisadora e à impossibilidade de se oferecer disciplinas sobre especificidades de autores e/ou linguagens (por conta da interdisciplinaridade das salas de aula, mencionada), levaram-me a buscar questões gerais dos processos de criação.

O acompanhamento teórico-crítico de vários processos gerou a observação de algumas características comuns nesses percursos, que viabilizou essa teorização de natureza geral dos processos de criação. O percurso da criação mostra-se como um emaranhado de ações que, em um olhar ao longo do tempo, deixam transparecer repetições significativas. É a partir 
dessas recorrências que se pôde estabelecer generalizações sobre o fazer criativo, a caminho de uma teorização. Não seriam modelos rígidos e fixos que, normalmente, mais funcionam como fôrmas teóricas que rejeitam aquilo que nelas não cabem. São instrumentos teóricos que permitem a ativação da complexidade do processo. Não guardam verdades absolutas, pretendem, porém, ampliar as possibilidades de discussão sobre o processo criativo.

Se os estudos genéticos ganharam em extensão na ampliação dos limites de manuscrito para além da literatura; já na busca por princípios de natureza geral, os estudos das singularidades ganham na profundidade de seus resultados, pois como afirma Colapietro "pensar é generalizar para lançar luzes sobre o específico". ${ }^{1}$

Sob esta perspectiva, tínhamos, no início da história do desenvolvimento da crítica genética, estudos propiciando conhecimento sobre as especificidades de alguns processos. A metodologia do estudo de documentos era, naquele momento, mais geral do que os resultados singulares, aos quais as pesquisas chegavam. Eram pesquisas que buscavam compreender as singularidades de determinados sujeitos em criação. À medida que uma possível teoria da criação é configurada, há uma inversão de perspectiva: a teorização passa a ser mais geral do que a metodologia restrita aos estudos de caso, que passa a estar a serviço de algo mais amplo, que é a teorização sobre o processo criador.

Trata-se de uma possível teoria da criação, que teve como ponto de partida estudos singulares de documentos e que, ao mesmo tempo, se alimenta permanentemente dessas mesmas pesquisas; deste modo, todas essas possibilidades de pesquisa vêm convivendo de forma bastante fértil. Há questões gerais nos processos, mas o que faz, por exemplo, teatro ser teatro ou o que caracteriza o processo de criação de um ator ou diretor específico?

Abre-se, também, a possibilidade de se desenvolver pesquisas comparadas, tanto no que diz respeito a diferentes autores de um mesmo meio de expressão ou entre processos de criadores de diferentes áreas.

$\mathrm{Na} 2^{a}$ edição do livro Crítica Genética: uma nova introdução, publicado em 2000, no capítulo "Crítica Genética em ação”, o estudo sobre literatura (Não Verás País Nenhum, de Ignácio de Loyola Brandão) da $1^{a}$ edição é

\footnotetext{
${ }^{1}$ Palestra no Programa de Comunicação e Semiótica da PUC/SP em 2014
} 
substituído por uma análise de esboços nas artes visuais de três artistas brasileiros (João Carlos Goldberg, Regina Silveira e Evandro Carlos Jardim), sob o ponto de vista da criação como transformação ${ }^{2}$, um dos aspectos que envolve a conceituação de criação que vem sendo desenvolvida.

A sistematização dessa possível teoria sobre os processos de criação é desenvolvida, ao longo do tempo, em interação com teóricos como Charles S. Peirce, Vincent Colapietro, Pierre Musso, Edgar Morin e Lotman.

O livro Gesto Inacabado: processo de criação artística, publicado em 1998, foi a primeira formulação dessa teorização, em diálogo com a semiótica de Peirce, mais especificamente, o conceito de semiose, propondo assim a leitura da criação como um processo sígnico. Essa base estava implícita nas primeiras edições e somente a partir da $5^{a}$ edição, revista e ampliada, o Posfácio explicita os aspectos da semiótica mais relevantes, utilizados como fundamentação teórica (SALLES, 2011).

Novas leituras, orientações e, especialmente, maior exposição a uma grande diversidade de registros de processos de criação geraram o livro Redes da criação: construção da obra de arte (2006), inserindo essa reflexão teórica no âmbito do pensamento da complexidade.

Não posso deixar de destacar, também, a relevância de se colocar disponível e dar atenção a algumas propostas que envolvem a experimentação contemporânea, em suas diversas manifestações, como veremos mais adiante.

\section{Ajustes Metodológicos e Terminológicos}

É interessante observar que a crítica genética, como seu próprio objeto, passa por ajustes, à medida em que vai se desenvolvendo. Em nome de sua expansão, sofre ajustes metodológicos e terminológicos. Como exemplo, temos a dificuldade de se usar o termo manuscrito ao lidar com outras manifestações artísticas. Busquei outra palavra: documentos de processo pareceu cumprir esta tarefa, dando destaque à função desempenhada pelos registros - necessidade de reter algumas ideias ou ações - e não à sua materialidade. Assim pode-se falar de documentos sob a forma de cadernos, anotações, diários, assim como ensaios teatrais, copiões, esboços etc., incluindo todo o

${ }^{2}$ Ver Salles $(2006,2011)$. 
potencial oferecido pelas mídias digitais. Nesta perspectiva, as novas tecnologias em vez de apontarem para o fim desses documentos, contribuem para o aumento da diversidade e sua ampliação constante.

Os registros analógicos e/ou digitais do percurso são feitos na linguagem mais acessível ao artista naquele momento, seja escrita, oral ou visual. Nesse contexto temos, por exemplo, os registros fotográficos e audiovisuais das artes cênicas enfrentando os desafios de documentar processos criativos no teatro, dança e performance.

A metodologia, por sua vez, também vem se mostrando em processo de expansão: muitos pesquisadores, especialmente no caso de teatro e cinema, passam a acompanhar processos, gerando outros documentos, sob a forma de anotações, fotografias, registros audiovisuais etc. Essa ampliação da metodologia é mostrada no capítulo "Crítica Genética em ação", da 3a edição do livro Crítica Genética, em 2008, no qual é relatado um processo de dança no Balé da Cidade de São Paulo, por mim acompanhado.

É interessante observar que muitas dessas questões fizeram parte do programa do Congresso "Tracing creation: genetics, genes and genealogies of performance” que aconteceu na Antuérpia /Bélgica (2016), que começa a discutir a crítica genética no âmbito da performance.

\section{Objetivos Renovados}

A partir dos rumos tomados pelas pesquisas na PUC/SP, a proposta passa a ser a compreensão dos processos de criação, a partir de metodologias diversas. Trata-se de uma alteração bastante significativa, que está estreitamente relacionada ao objetivo de conceituar criação.

Todas essas questões se refletem nas discussões do Centro de Estudos, que opta por mudar seu nome, passando a ser Grupo de Estudos em Processos de Criação. A opção por Grupo de estudos justifica-se por ser o termo usado pela plataforma do CNPq e Processos de criação, respondendo às inquietações dos alunos e minhas, em relação aos rumos que as pesquisas tomaram e às restrições à denominação crítica genética.

A dificuldade enfrentada pelo uso dessa terminologia diz respeito ao conceito de gênese, que tem fortes resquícios de busca e, portanto, crença na existência de origem. A conceituação da criação como semiose, ou seja, 
como processo contínuo, ressalta a regressão e progressão infinitas do signo. Continuidade significa, portanto, a destruição do mito do signo originário e do último absoluto. Estando o signo em progressão e regressão infinitas, destrói-se o ideal de um começo e de um fim absolutos.

$\mathrm{Na}$ verdade, esse aspecto do conceito de criação foi gerado pela leitura de inúmeras anotações que encontrei nos diários de Loyola, (e de muitos outros artistas), de "certezas" de encontros de onde o livro havia nascido e também de inúmeros possíveis pontos finais.

Trago para essa discussão uma experiência pela qual passei no grupo sobre Gêneses Cinematográficas no ITEM/CNRS, coordenado por Daniel Ferrer e Jean-Loup Bourget (ITEM/CNRS), quando apresentei alguns resultados dos estudos que fiz dos extras e bônus dos DVDs de filmes, de modo mais específico, as faixas comentadas por membros da equipe de produção dos filmes, como diretores, montadores ou atores.

Minha escolha foi questionada, pois eram dados posteriores à estreia do filme. Falei que eram registros que guardam uma forte semelhança com textos retrospectivos da literatura, como o sempre tão citado, Filosofia da Composição de Edgar Allan Poe, História Secreta de una Novela, de Mário Vargas Llosa, entre tantos outros normalmente citados pelos críticos genéticos.

Ao mesmo tempo, esses comentários posteriores, não são em nada diferentes de muitas anotações que encontrei nos cadernos do artista visual Daniel Senise, discutidas por mim em outro seminário no ITEM e não questionadas. Em que são diferentes? Por ser em linguagem verbal escrita? Por estar em cadernos de artistas, reconhecidos por objetos da crítica genética?

O impasse diante das diferentes materialidades e temporalidades, a meu ver, camufla a necessidade de ter respaldo em algum conceito de criação, para se tomar ou não como objeto do pesquisador interessado em processos de criação.

Destaco, neste contexto, outros aspectos da criação, presentes na teorização que venho sistematizando, que são a não linearidade e o incabamento, intrínsico à continuidade. $O$ tempo da reflexão não cessa quando o filme estreia, a exposição é aberta ou o livro é publicado. As reflexões posteriores a esse momento são inevitáveis, e parte integrante de suas buscas, que estão sempre em processo. 
Essas ilustrações foram trazidas para discutir a relevância da interação dos estudos genéticos com a necessidade de uma conceituação de criação, que acredito ser um dos marcos mais relevantes da singularidade das pesquisas desenvolvidas na PUC/SP.

Por esse motivo optei pela apresentação, de maneira sucinta, do conceito de criação como rede em construção. Trata-se da proposta de interação do conceito de rede de Pierre Musso (2004) e semiose em termos peirceanos, em diálogo com pensadores da cultura como Edgar Morin e Yuri Lotman.

A criação como rede pode, assim, ser descrita como um processo contínuo de interconexões, com tendências vagas, gerando nós de interação, cuja variabilidade obedece a princípios direcionadores. Esse processo contínuo, sem ponto inicial nem final, é um movimento falível, sustentado pela lógica da incerteza, englobando a entrada de ideias novas. As interconexões nos colocam no campo relacional: toda ação está relacionada a outras ações de igual relevância, sendo assim um percurso não linear e sem hierarquias. As interconexões geram os picos ou nós da rede, elementos de interação ligados entre si, que se manifestam como os eixos direcionadores de nossas pesquisas, ou seja, as recorrências encontradas nos documentos estudados.

As tendências são rumos vagos, que orientam o processo de construção dos objetos, no ambiente de incerteza e imprecisão. As tendências podem ser observadas sob duas perspectivas: constituição de projetos poéticos ou princípios direcionadores e práticas comunicativas.

Nesse contexto de tendências vagas está, portanto, o projeto do artista, que são princípios direcionadores, de natureza ética e estética, presentes nas práticas criadoras, relacionados à produção de uma obra específica e que atam a obra daquele criador, como um todo. São as teorias implícitas no fazer, relativas à singularidade do artista. Esse projeto está inserido no espaço e tempo da criação, que inevitavelmente afetam o artista. A busca, como processo contínuo, é sempre incompleta. O próprio projeto, que direciona de algum modo a produção das obras, muda ao longo do tempo.

Quanto às reflexões sobre as tendências dos processos sob o ponto de vista das práticas comunicativas, pode-se afirmar que o processo de criação se mostra, também, como uma tendência para outros, na medida em que está inserido nas complexas redes culturais. $\mathrm{O}$ aspecto comunicativo do processo envolve sujeitos como comunidade, travando uma grande diversidade de outros diálogos de natureza inter e intrapessoais, como com 
a obra em processo, com futuros receptores, com a crítica e com os membros dos grupos etc.

Já a o percurso de construção da rede ou a "recompensa material" (Kandinsky, 1990) inclui sua dinâmica e está inserido no espaço e tempo da criação, que inevitavelmente afetam o realizador ou agente criativo.

Ao longo deste processo, vão sendo estipuladas restrições ou delimitações de naturezas diversas que tornam a construção da obra possível. O desenvolvimento do processo leva a tomadas de decisão que propiciam a formação de linhas de força, dando consistência aos objetos em construção ${ }^{3}$.

As pesquisas sobre as especificidades partem dessas questões gerais e buscam os nós da rede (os aspectos mais relevantes) daquele processo específico.

\section{Linha de Pesquisa}

Destaco, também, nessa história de expansão da crítica genética, a formação da linha de pesquisa Processos de criação nas mídias, no Programa de Comunicação e Semiótica (PUC/SP), que mais tarde passou a ser chamada Processos de Criação na Comunicação e na Cultura.

\section{Diálogo com a Experimentação Contemporânea}

Trago, por último, outra questão que acredito ser relevante na caracterização dessa ampliação do campo de ação da crítica genética, São pesquisas que partem também de indagações diante da produção contemporânea e seus desafios teórico-críticos.

Trata-se de uma produção que fala de um vasto campo de experimentação, envolvendo, entre tantas outras questões, o apagamento de fronteiras entre processo de criação e a obra mostrada publicamente e entre arquivos privados e públicos. O processo de criação extravasa, em muitas propostas artísticas, os bastidores e passa a integrar a malha dos objetos em criação.

${ }^{3}$ Nos livros Gesto incabado e Redes da criação (SALLES, 2011 e 2006, respectivamente), essas questões são apresentadas de modo aprofundado sempre em diálogo com os dados oferecidos por agentes criativos em sua grande diversidade de manifestações. 
A teorização sobre os processos de criação passa, portanto, a oferecer uma perspectiva crítica de natureza processual que, se levada às últimas consequências, não se limita a documentos de processo, que pertencem ao passado das obras. Ao olhar retrospectivo da crítica genética, está sendo adicionada uma dimensão prospectiva, de obras que são processuais. Em outras palavras, são obras que são redes em permanente construção, falando de um processo, mas não mais privado. Cada versão da obra pode ser vista de modo isolado, mas se assim for feito, perde-se algo que a natureza da obra exige. São obras que nos colocam diante da estética do inacabado, nos incitam a seu melhor conhecimento e o consequente acompanhamento crítico dessas mutações, não podendo deixar de lado todo o potencial da experimentação nas mídias digitais.

Como se pode observar, algumas obras contemporâneas (mas não só) impuseram novas metodologias para compreender seus processos construtivos e, ao mesmo tempo, reconceituaram tanto processo de criação, como obra.

Para nos aproximarmos desses diferentes vínculos entre processo e obra, o crítico precisa de instrumentos teóricos que sejam capazes de discutir obras em sua dinamicidade. Uma abordagem que compreenda a criação em sua natureza de rede complexa de interações em permanente mobilidade. As leituras dos objetos estáticos não são satisfatórias, parecem deixar de lado algo de determinante que está na obra e que, no entanto, não consegue nem ser tocado ou atingido.

É neste contexto que passei a discutir essa teorização da criação como uma proposta para uma crítica de processos de criação, para além de algumas delimitações da crítica genética.

\section{Referências}

FERRER, D. A crítica genética do século XXI será transdisciplinar, transartística e transemiótica ou não existirá. In: WILLEMART, P. (Org.) Fronteiras da criação: VI Encontro Internacional de Pesquisadores do Manuscrito. São Paulo: Annablume, 2000. 
SALLES, C. A. Crítica Genética: uma introdução. São Paulo: Educ, 1992.

SALLES, C. A. Crítica Genética: uma nova introdução. 2. ed. São Paulo: Educ, 2000.

SALLES, C. A. Redes da criação: construção da obra de arte. Vinhedo: Horizonte, 2006.

SALLES, C. A. Crítica Genética: fundamentos dos estudos genéticos sobre o processo de criação artística. 3. ed. São Paulo: Educ, 2008.

SALLES, C. A. Gesto Inacabado: processo de criação artístico. 5. ed. São Paulo: Intermeios, 2011.

Enviado em: 03/10/2016 Aceito em: 10/11/2016 